\title{
Investigation of leucinuria as a marker of progression of type 2 diabetes mellitus
}

\section{Pokharel KK', Pradhan S ${ }^{2}$}

${ }^{1}$ Kabita Khaniya Pokharel, Lecturer; Department of Biochemistry, Kathmandu Medical College Basic Sciences, Duwakot, Bhaktapur, Nepal; ${ }^{2}$ Santosh Pradhan, Department of Biochemistry, Samyak Diagnostic, Lalitpur, Nepal.

\begin{abstract}
Background: The prevalence of diabetes is increasing worldwide leading to an extreme burden in healthcare system. Insulin resistance plays a major role in the pathogenesis of type 2 diabetes mellitus. A number of studies have been done to investigate the role of leucine in insulin resistance. These studies have elucidated raised serum leucine level in type 2 diabetes mellitus.

Objectives: The objective of this study was to determine leucine in random urine of type 2 diabetes mellitus and to assess the association of urine leucine with the progression of the disease.

Methodology: An analytical cross-sectional study was carried out in 187 participants after ethical approval. Patients already diagnosed with chronic kidney disease were excluded from the study. Urine microalbumin level was determined by nephelometry technique, $\mathrm{HbA} 1 \mathrm{c}$ test was done by high performance liquid chromatoghrapy and urine leucine was detected by thin layer chromatography method.

Results: The mean age of the case population was $55.7 \pm 11.6$ years and that of control population was $49.98 \pm 13.7$ years. Out of 105 cases, 15 (14.3\%) of them had leucine in random urine where as only 3 (3.6\%) of them from control showed the presence of leucine in their urine. There was a significant association observed between diabetic patient and urinary leucine excretion, $\mathrm{P}=0.014$.

Conclusion: This study indicates an association of type 2 diabetes and urinary leucine excretion. However, presence of leucine in urine does not suggest the progression of the disease.
\end{abstract}

Key words: Diabetes; Leucine; Thin layer Chromatography.

DOI: https://doi.org/10.3126/jkmc.v8i1.25266

\section{INTRODUCTION}

$\mathrm{D}$ iabetes mellitus (DM) is a metabolic disease, where the body cannot regulate the amount of glucose in the blood ${ }^{1}$. The prevalence of Diabetes in Nepal is $6.3 \%{ }^{2}$, and is increasing every day ${ }^{3}$. A common and morbid complication of DM is diabetic kidney disease which is a leading cause of chronic kidney disease ${ }^{4}$.

The association between branched chain amino acid (BCAA) and insulin resistance or T2DM has long been recognized $^{5}$. Serum level of leucine, isoleucine and valine which are the BCAAs, are being investigated as potential

\section{Address for correspondence}

Dr. Kabita Khaniya Pokharel

Department of Biochemistry

Kathmandu Medical College Teaching Hospital

Duwakot, Bhaktapur

E-mail:kabitakhaniya@gmail.com biomarkers for risk prediction of $\mathrm{T}_{2} \mathrm{DM}^{6,7}$. Several studies have correlated BCAA with $\mathrm{T}_{2} \mathrm{DM}^{8-12}$ but there are limited studies which have explored their occurrence in the urine of diabetic patients.

Glycated hemoglobin or HbA1c identifies the three month average plasma glucose concentration and assesses the glycemic control in people with diabetes. Microalbuminuria is the earliest clinical evidence of nephropathy in diabetes mellitus with the appearance of low but abnormal level (30-300mg/day) of albumin in the urine suggesting the progression of the disease.The goal of our study was to observe the presence of leucine in the urine of diabetic patients and to assess whether its presence can suggest the progression of the disease.

\section{METHODOLOGY}

An analytical cross-sectional study was carried out over a period of four months (from June 2018 to September 
2018). The study group consisted of 105 Type 2 Diabetic patients of age group 30-80. 82 age and sex matched non diabetic controls were selected for comparison. The sampling method used in this study was convenience sampling. Diabetic patients (for case) and non diabetic patients (for comparison) visiting Kathmandu Medical College and Teaching Hospital were included in the study. Patients with already diagnosed chronic kidney disease were excluded for both case and control.

Ethical clearance for carrying out Thin Layer Chromatography (TLC) of urine of cases and controls was obtained from institutional review board, (KMCTH), Sinamangal and samples were collected only after informed consent.

Random urine samples of all subjects were collected for analysis, and stored at $-20^{\circ} \mathrm{C}$ until the TLC was performed. TLC plate was made in the biochemistry laboratory of KMC, Basic Sciences with a slurry of silica gel G (silica gel with gypsum binder) layered on the glass plate with the help of an applicator. Thin layer chromatography was performed on all samples with solvent mixture consisting of butanol, acetic acid and water in the ratio of 4:1:1. A $2 \%$ solution of leucine (solvent used was water with few drops of hydrochloric acid to dissolve leucine) was run alongside the samples for comparing the migrations of urinary amino acids.

While performing TLC, the volume of urine loaded on the plate was based on creatinine content, estimated by Jaffe's method, to correct for the variation in urine concentration. A volume of urine containing $4 \mu \mathrm{gm}$ creatinine was used. The volume of urine calculated from the creatinine content was applied by a micropipette with air drying to limit the spot size to $0.8 \mathrm{~cm}$ in diameter. The plate was then carefully placed in a chromatography jar containing the solvent for 2.5 hours to allow the separation of amino acids to occur. Then the plate was air dried and sprayed with ninhydrin to visualize the separation. Retardation factor (the total distance covered by individual spot relative to the distance moved by the solvent) was calculated for samples which showed similar migration as that of leucine standard (Figure 1).

HbA1C was determined by BioRad D10 which operates on the principle of high performance liquid chromatography (HPLC). The column comprises of small cation exchange cartridge. The samples are injected into the analysis stream and separated by the cation exchange cartridge using a phosphate ion gradient generated by mixing two buffers of different ionic strengths to elute the different hemoglobins. A dual wavelength filter photometer monitors the eluent from the cartridge as it passes through the photometer cell. Changes in optical density at $415 \mathrm{~nm}$ are measured. A secondary filter at $650 \mathrm{~nm}$ corrects the effects caused by mixing buffers of different ionic strengths.

Urine for microalbumin was determined by Mispa-i3, nephelometry method. Here latex particles coated with antihuman albumin are agglutinated when mixed with sample containing albumin. The agglutination causes an absorbance change depending upon the albumin concentration of sample. The amount of agglutination is measured to calculate microalbumin concentration from a calibration curve.

Data analysis was done using SPSS version 22.0 (IBM Corporation, Armonk, NY, USA). Normally distributed variables were expressed as mean \pm standard deviation and variables without normal distribution as medians (range). Independent t-test and Mann-Whitney $U$ test was used for comparing means and medians respectively. Chi-square test was used for comparison of proportions between variables.

\section{RESULTS}

A total of 187 participants were included in our study. The mean age of the case population was $55.7 \pm 11.6$ years and that of control population was $49.98 \pm 13.7$ years. $60(57.15 \%)$ and 45 (42.85\%) of case was represented by male and female diabetic patient respectively. Table 1 shows the demographic and biochemical characteristics of the study population.

Out of 105 cases, 15 (14.3\%) of the urine samples were positive for leucine, whereas only $3(3.6 \%)$ from the control group showed the presence of leucine (Figure 2). Significant association was observed between the presence of diabetes and urinary leucine excretion, $2(1)=5.9$, $(n=187, p=0.014)$. There was no significant difference in leucinuria based on gender, with $6.6 \%$ of males and $7.6 \%$ of females from cases having leucine in their urine. Leucinuria in diabetic patients, however, was not significantly associated with microalbuminuria or Glycated hemoglobin or age (Table 2).

Measuring microalbumin and $\mathrm{HbA1c}$ is a costly investigation which is advised regularly to only diabetic patients. So their reports were available from cases but as these tests are not routinely done in non diabetic patients, the reports were not available for control population. 
Diabetic cases were categorized according to their $\mathrm{HbA} 1 \mathrm{c}$ value into group $\mathrm{A}(\mathrm{HbA} 1 \mathrm{c} \leq 6.5 \mathrm{gm} \%)$ as having good glycemic control and group B (HbA1c $\geq 6.5 \mathrm{gm} \%)$ as having poor glycemic control. A higher percentage of cases from the poor glycemic control group showed leucinuria (Figure 3).
(A multiple regression was run to predict Leucinurea from $\mathrm{HbA} 1 \mathrm{c}$ and urine microalbumin. These variables could not predict Leucinuria with statistical significance, $F(2$, 103) $=1.23, \mathrm{p}<.029, \mathrm{R} 2=.23)$

\section{Table 1: Demographic and biochemical characteristics of the study population}

\begin{tabular}{lccc}
\hline Variable & Case $(\mathbf{n = 1 0 5})$ & Control $(\mathbf{n = 8 2})$ & $\boldsymbol{P}$-value \\
Age (Mean years) & $55.7 \pm 11.6$ & $49.98 \pm 13.7$ & 0.08 \\
Gender & & & \\
Male/Female & $60 / 45$ & $36 / 46$ & 0.06 \\
\hline Microalbumin (mg/L) & $17.7(1-668)$ & NA & NA \\
HbA1c (\%) & $7.4(5.3-18.4)$ & NA & NA \\
\hline
\end{tabular}

Table 2: Association between urine leucine and different parameters in diabetic patient

\begin{tabular}{lc} 
Parameters & $\begin{array}{c}\text { P-value (Independent } \\
\text { t-test) }\end{array}$ \\
\hline Age (years) & 0.30 \\
Microalbumin (mg/L) & 0.60 \\
\hline HbA1c (\%) & 0.36 \\
\hline
\end{tabular}

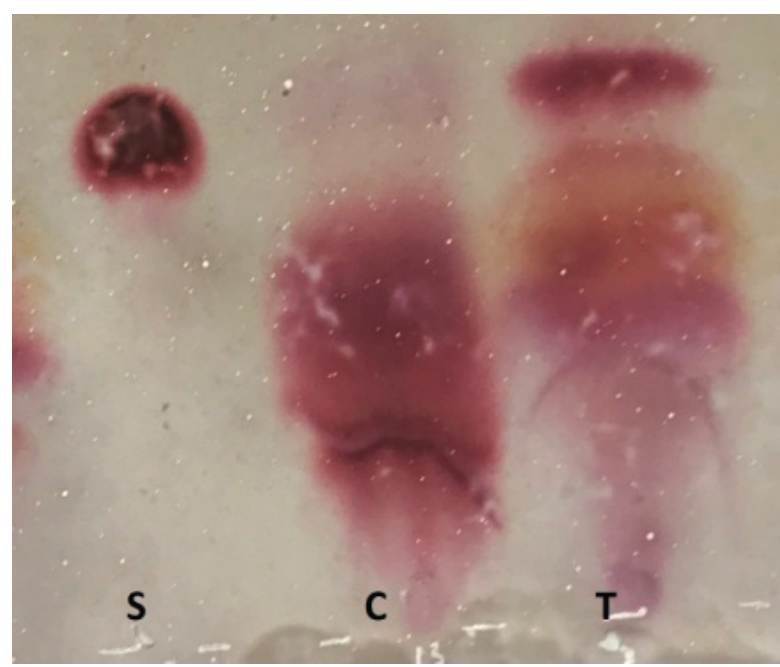

Figure 1:TLC plate after staining with ninhydrin

( $\mathrm{S}$ is the standard for leucine, $\mathrm{C}$ is the control sample and $\mathrm{T}$ is the diabetic sample, arrow showing the leucine band)

\section{DISCUSSION}

In this study, the presence of leucine, which is a BCAA, in urine of diabetic patients was assessed and compared with the non diabetic controls. It was found that more diabetic patients excreted leucine in urine as compared to non diabetic control. Similar results have been found in another study by Kolanuet $a l^{13}$.

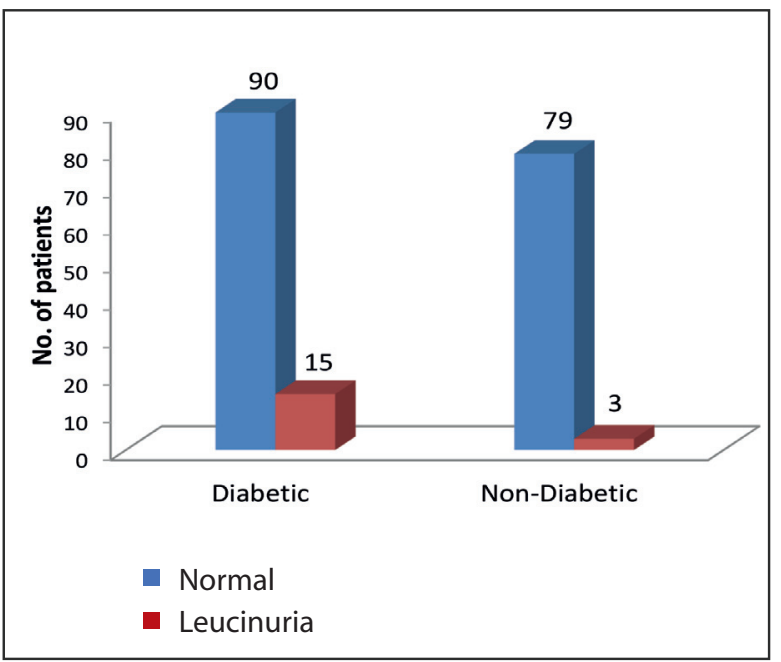

Figure 2: A bar graph representing urine leucine status of diabetics and non-diabetics

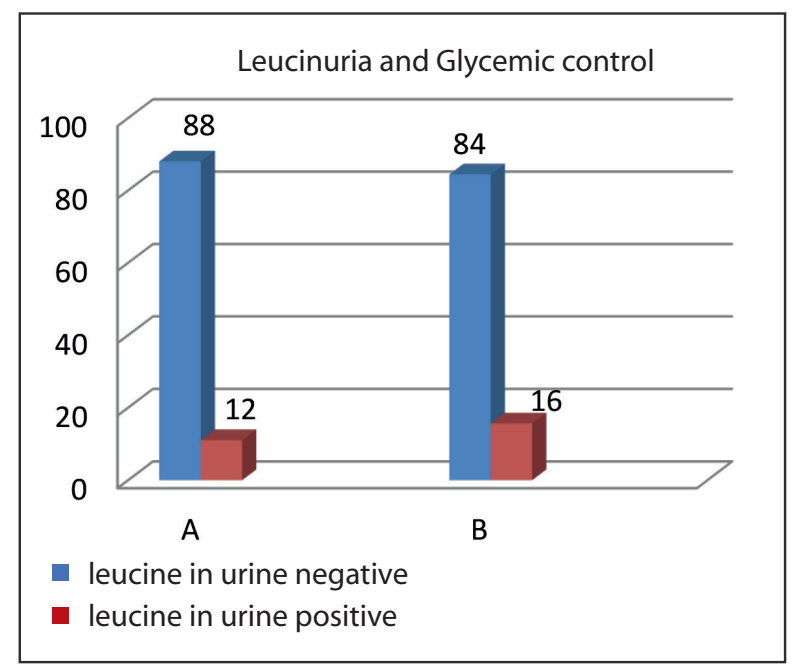

Figure 3: Percentage of leucinuria in diabetics with good (A) and poor (B) glycemic control. 
Many studies have shown the association between increased circulating levels of BCAA and type 2 Diabetes Mellitus, not only that there is high serum BCAA in T2DM but also that they mediate the risk for future diabetes since they are markers for the development of insulin resistance ${ }^{11,12,14-16}$. Two mechanisms are proposed to explain the link between metabolic disease and elevated level of BCAA. One is that elevated level of BCAA would stimulate mammalian target of rapamycin complex 1 (mTORC1), which leads to uncoupling of insulin signaling. Secondly, the mitotoxic metabolite of BCAA causes mitochondrial dysfunction of beta cells of pancreas aggravating $\mathrm{T}_{2} \mathrm{DM}^{14,17}$. It has also been shown to regulate gene transcription and protein synthesis in pancreatic islet beta cells via mammalian target of rapamycin (mTOR)-dependent pathways as well as mTOR independent pathways at physiological concentration ${ }^{18,19}$. Moreover, studies in mice have shown that leucine deprived food significantly reduces hyperglycemia together with improved glucose tolerance and insulin sensitivity ${ }^{17,20}$.

If serum level of BCAA is high in T2DM, they should be excreted in urine as well. This could be the reason for finding leucinuria in diabetic patients in this study. The reason could be similar to that of maple syrup disease where branched chain keto acid dehydrogenase dysfunction results in elevation of BCAA in serum and excretion of the same in urine. ${ }^{21}$

The estimation of BCAA in serum requires a well equipped laboratory with much more expensive and advanced tests like HPLC, Nuclear magnetic resonance (NMR) spectroscopy ${ }^{11}$, Liquid chromatography-Mass spectrometry ${ }^{12}$. Qualitative estimation of leucine in urine by TLC is a simple and cheaper technique which could be an alternative for estimation of serum leucine.

In this study, the presence of leucine in urine of diabetic patients and their $\mathrm{HbA} 1$ clevel was assessed, no significant association was found between the presence of leucine in urine and the value of $\mathrm{HbA} 1 \mathrm{c}$. In a study by Badaud et $\mathrm{a}^{22}$, similar finding was observed when they correlated serum leucine level with $\mathrm{HbA} 1 \mathrm{c}$ level and Homeostatic Model Assessment for Insulin Resistance (HOMA IR). They found the positive correlation of serum leucine with HOMA IR but not with $\mathrm{HbA1C}$. However, they found that other branched chain amino acid like valine and isoleucine were positively associated with both $\mathrm{HbA1c}$ and HOMA IR. Moreover, when we categorized the cases in the study group according to their $\mathrm{HbA1c}$ value into group A ( $\mathrm{HbA} 1 \mathrm{c} \leq 6.5 \mathrm{gm} \%)$ as having good glycemic control and group B (HbA1c $\geq 6.5 \mathrm{gm} \%$ ) as having poor glycemic control, a higher percentage of cases from the poor glycemic control group showed leucinuria.

In addition, the microalbumin, which is the established biomarker of nephropathy in diabetics, was assessed to compare its level with leucinuria to see whether leucinuria can predict the development of nephropathy. However, no association was found between presence of leucine in urine of diabetic patient and the level of microalbumin.

One of the limitations of our study is that we have not considered the drugs (hypoglycemic drugs or other drugs for co-morbid conditions) that were taken by the patients which might have some role in urinary excretion of leucine.

\section{CONCLUSION}

On the basis of findings, it can be concluded that there is association between type 2 diabetes and urinary leucine excretion. However, presence of leucine in urine does not suggest the progression of the disease.

\section{ACKNOWLEDGEMENTS}

We would like to thank all the staffs working in Biochemistry Laboratory, KMC for the help and support.

\section{REFERENCES}

1. Olokoba $A B$, Obateru OA, Olokoba LB. Type 2 diabetes mellitus: a review of current trends. Oman medical journal. 2012;27(4):269-73 [PubMed]

2. Sharma SK, Ghimire A, Radhakrishnan J, Thapa L, Shrestha NR, Paudel N, et al. Prevalence of hypertension, obesity, diabetes, and metabolic syndrome in Nepal. International journal of hypertension. 2011;2011:821971.[PubMed]

3. Whiting DR, Guariguata L, Weil C, Shaw J. IDF diabetes atlas: global estimates of the prevalence of

diabetes for 2011 and 2030. Diabetes research and clinical practice. 2011;94(3):311-21.[Full Text]

4. de Boer IH, Rue TC, Hall YN, Heagerty PJ, Weiss NS, Himmelfarb J. Temporal trends in the prevalence of diabetic kidney disease in the United States. Jama. 2011;305(24):2532-9.[Full Text]

5. Felig P, Marliss E, Cahill GF, Jr. Plasma amino acid levels and insulin secretion in obesity. The New England journal of medicine. 1969;281(15):811-6. [Full Text] 
6. Giesbertz P, Daniel H. Branched-chain amino acids as biomarkers in diabetes. Current opinion in clinical nutrition and metabolic care. 2016;19(1):48-54. [PubMed]

7. Shah SH, Svetkey LP, Newgard CB. Branching out for detection of type 2 diabetes. Cell metabolism. 2011;13(5):491-2.[DOI]

8. Newgard CB, An J, Bain JR, Muehlbauer MJ, Stevens $R D$, Lien $L F$, et al. $A$ branched-chain amino acidrelated metabolic signature that differentiates obese and lean humans and contributes to insulin resistance. Cell metabolism. 2009;9(4):311-26. [PubMed]

9. Huffman KM, Shah SH, Stevens RD, Bain JR, Muehlbauer $M$, Slentz CA, et al. Relationships between circulating metabolic intermediates and insulin action in overweight to obese, inactive men and women. Diabetes care. 2009;32(9):1678-83. [DOI]

10. Weng L, Quinlivan E, Gong Y, Beitelshees AL, Shahin $\mathrm{MH}$, Turner ST, et al. Association of Branched and Aromatic Amino Acids Levels with Metabolic Syndrome and Impaired Fasting Glucose in Hypertensive Patients. Metabolic Syndrome and Related Disorders. 2015;13(5):195-202.[PubMed]

11. Wurtz $P$, Soininen $P$, Kangas AJ, Ronnemaa $T$, Lehtimaki $T$, Kahonen $M$, et al. Branched-chain and aromatic amino acids are predictors of insulin resistance in young adults. Diabetes care. 2013;36(3):648-55.[DOI]

12. McCormack SE, Shaham O, McCarthy MA, Deik AA, Wang TJ, Gerszten RE, et al. Circulating branchedchain amino acid concentrations are associated with obesity and future insulin resistance in children and adolescents. Pediatric obesity. 2013;8(1):52-61. [PubMed]

13. Kolanu BR, Boddula V, Vadakedath S, Kandi V. Amino Acid (Leucine) Chromatography: A Study of
Branched-Chain Aminoaciduria in Type 2 Diabetes. Cureus. 2017;9(3):e1091.[PubMed]

14. Lynch CJ, Adams SH. Branched-chain amino acids in metabolic signalling and insulin resistance. Nature reviews Endocrinology. 2014;10(12):723-36.[DOI]

15. Wang TJ, Larson MG, Vasan RS, Cheng S, Rhee $E P, M c C a b e ~ E$, et al. Metabolite profiles and the risk of developing diabetes. Nature medicine. 2011;17(4):448-53.[DOI]

16. Newgard CB. Interplay between lipids and branchedchain amino acids in development of insulin resistance. Cell metabolism. 2012;15(5):606-14. [PubMed]

17. Wei S, Zhao J, Wang S, Huang M, Wang Y, Chen Y. Intermittent administration of a leucine-deprived diet is able to intervene in type 2 diabetes in $\mathrm{db} / \mathrm{db}$ mice. Heliyon. 2018;4(9):e00830.[PubMed]

18. Yang J, Chi Y, Burkhardt BR, Guan Y, Wolf BA. Leucine metabolism in regulation of insulin secretion from pancreatic beta cells. Nutrition reviews. 2010;68(5):270-9. [DOI]

19. Stipanuk MH. Leucine and protein synthesis: mTOR and beyond. Nutrition reviews. 2007;65(3):122-9. [DOI]

20.Xiao F, Huang Z, Li H, Yu J, Wang C, Chen S, et al. Leucine deprivation increases hepatic insulin sensitivity via GCN2/mTOR/S6K1 and AMPK pathways. Diabetes. 2011;60(3):746-56. [DOI]

21. Chapman K. A., Gramer G., Viall S., Summar M. L. Incidence of maple syrup urine disease, propionic acidemia, and methylmalonic aciduria from newborn screening data. Molecular genetics and metabolism reports. 2018; 15: 106-109. [PubMed]

22. Badoud F, Lam KP, DiBattista A, Perreault M, Zulyniak MA, Cattrysse B, et al. Serum and adipose tissue amino acid homeostasis in the metabolically healthy obese. Journal of proteome research. 2014;13(7):3455-66. [FullText] 